\title{
ARTIGO
}

\section{Critérios de qualidade em artigos e periódicos científicos: da mídia impressa à eletrônica ${ }^{1}$}

\author{
Criteria of quality for scientific articles and \\ journals: from printed media to electronic media
}

Maria Fernanda SARMENTO e SOUZA²

Silvana Aparecida Borsetti Gregório VIDOTTI ${ }^{3}$

M iriam Celí Pimentel Porto FORESTI ${ }^{4}$

RE S U M O

Esta revisão sintetiza o histórico e o papel da comunicação científica, em particular as mudanças ocorridas diante do surgimento das redes eletrônicas de comunicação e computação. Resgata-se o processo evolutivo e as funções básicas do periódico científico - memória e disseminação - considerado principal instrumento de comunicação da ciência. Apontam-se critérios de qualidade de periódicos científicos impressos que devem ser mantidos na estrutura das revistas eletrônicas, a fim de garantir a permanência das funções memória e disseminação; consideram-se, ainda, novos elementos estruturais a serem implementados. O trabalho faz parte de um projeto cuja finalidade é implementar um modelo que possa contribuir com profissionais bibliotecários, autores e

\footnotetext{
${ }^{1}$ Este artigo foi publicado originalmente em espanhol com a seguinte referência: SARMENTO E SOUZA, M.F.; FLOREST, M.C.P.P.; VIDOTTI, S.A.B.G. Criterios de calidad en artículos y periódicos científicos: de la midia impressa a la eletrónica. Ciencias de la Información, Habana, Cuba. v.34, n.1, p.39-54, 2003.

2 Mestranda em Ciência da Informação, Universidade Estadual Paulista. Av. Hygino Muzzi Filho, 737, Campus Universitário, 17525-900, Marília, SP, Brasil. Membro do Grupo de Pesquisa - Novas Tecnologias da Informação, E-mail: fsarmento@cevap.org.br ou fernanda sarmento@yahoo.com

3 Docente, Departamento de Ciência dā Informação, Universidade Estadual Paulista. Av. Hygino Muzzi Filho, 737, Campus Universitário, 17525-900, Marília, SP, Brasil. Membro do Grupo de Pesquisa - Novas Tecnologias da Informação, E-mail: vidotti@marilia.unesp.br

4 Docente, Departamento de Educação, Instituto de Biociências, Curso de Pós-Graduação em Ciência da Informação, Membro do Grupo de Pesquisa - Novas Tecnologias da Informação, Universidade Estadual Paulista, Distrito de Rubião Jr, s/noㅡ, Rubião Jr., 18618-000, Botucatu, SP, Brasil. E-mail: mforesti@ibb.unesp.br Recebido em 22/4/2003 e aceito para publicação em 23/4/2004.
} 
usuários de revistas científicas, na identificação de periódicos eletrônicos de qualidade e com editores de revistas em linha, no desenvolvimento de seus projetos. O material de estudo poderá ser incluído em programas de formação inicial e continuada de profissionais da Ciência da Informação e em projetos de assessoria a editores de revistas científicas eletrônicas.

Palavras-chave: comunicação científica, ciência da informação, Internet, periódico científico eletrônico.

\section{A B S T R A C T}

This revision sums up the curriculum and the role of the scientific communication, in particular, the changes that occurred due to the emergence of the electronic network of communication and data processing. The process of evolution and the basic functions of the scientific journal-memory and distribution-are reviewed, as they are considered the main instrument of the scientific communication. Also Indicated is the criteria of quality of printed scientific journals that should be kept in the electronic magazines' structure, in order to ensure the permanence of functions such as memory and dissemination, yet considering new structural elements to be implemented. This work is part of a project whose objective is to implement a model that could contribute to the task of librarians, authors and scientific magazine users, in identifying electronic journals of quality, and that of publishers of magazines, in developing their projects. The study's resulting material could be included in the education programs of information science professionals, as well as be used as a projects' supporting tool for publishers and electronic scientific magazines.

Key words: scientific communication, information science, Internet, electronic scientific journals.

\section{A Comunicação científica: evolução histórica}

A comunicação científica, atualmente passando por um processo radical de mudança, sempre teve como principal função disseminar e tornar disponível o conhecimento científico.

\footnotetext{
A comunicação situa-se no próprio coração da ciência. É para ela tão vital quanto a própria pesquisa, pois a esta não cabe reivindicar com legitimidade este nome enquanto não houver sido analisada e aceita pelos pares. Isso exige, necessariamente, que seja
}

comunicada. Ademais, o apoio às atividades científicas é dispendioso, e os recursos financeiros que lhes são alocados serão desperdiçados a menos que os resultados das pesquisas sejam mostrados aos públicos pertinentes. Qualquer que seja o ângulo pelo qual a examinemos, a comunicação eficiente e eficaz constitui parte essencial do processo de investigação científica (MEADOWS, 1999, p.vii).

Durante o processo de comunicação, o autor precisa estar atento a alguns requisitos 
básicos, tais como: "o conhecimento daquilo que se comunica, a precisão terminológica, a acessibilidade da linguagem, a adaptação à audiência". (MEDEIROS, 2000, p.186).

Não se sabe ao certo quando ocorreu a primeira pesquisa científica e, conseqüentemente, a primeira comunicação científica. Sabe-se que os debates sobre questões filosóficas e outras atividades exercidas pelos gregos nos séculos V e IV a.C. influenciaram a comunicação científica moderna e que eles se valiam da fala e da escrita para comunicar suas pesquisas (MEADOWS, 1999).

Com a invenção da imprensa no século $\mathrm{XV}$, houve um grande aumento na disponibilidade de textos impressos na Europa, o que desencadeou o crescimento da produção média de livros, causando um impacto na difusão das informações, conforme salientou Barnaby Rich em 1613 citado por Kronick (1976c):

Um dos males destes tempos é a multiplicidade de livros; eles, de fato, sobrecarregam de tal modo a gente que não conseguimos digerir a abundância de matéria inútil que, todos os dias, é gerada e despejada no mundo (KRONICK, 1976c, p.171).

A transição da forma manuscrita para a forma impressa não foi rápida. A capacidade de reproduzir um livro era um passo muito importante para a difusão das pesquisas (MEADOWS, 1999), além de eliminar erros que surgiam durante a transcrição de um material e permitir a utilização de tabelas e imagens nos textos científicos (BELMAR; SÁNCHEZ, 2001). No entanto, como os noticiários, os livros e as cartas pregavam idéias suscetíveis de censura, permanecendo em circulação na forma manuscrita até o século XVIII. Para a pesquisa, era interessante que as idéias circulassem por meio de cartas, para grupos restritos, que pudessem analisar os resultados e, quando conveniente, testar os métodos utilizados, encaminhando posteriormente uma resposta (KRONICK, 1976a;
MEADOWS, 1999). Esses grupos foram a base para a criação das sociedades e academias científicas. Séculos mais tarde, esse tipo de organização informal para intercâmbio de idéias continua existindo, denominando-se 'colégios invisíveis' (STUMPF, 1996).

Pelo fato de as cartas serem muito pessoais, um processo lento para a divulgação de novas idéias e limitadas a um pequeno grupo de pessoas, essas dissertações epistolares, como foram chamadas por McKie citado por Stumpf (1996), não se constituíram no método ideal para a comunicação do fato científico e das teorias. Quando o conteúdo das cartas se destinava a um grupo maior de pessoas, eram enviadas às sociedades científicas que as imprimiam e distribuíam à comunidade surgindo, assim, as primeiras revistas científicas, na segunda metade do século XVII (MEADOWS, 1999; PRICE, 1976).

A introdução do periódico significou a formalização do processo de comunicação científica, tornando-se o canal formal de divulgação ao possibilitar que as pesquisas fiquem disponíveis por longos períodos de tempo para um público amplo (MEADOWS, 1999).

Para Ziman (1979), as revistas científicas, criadas pelas sociedades reais e academias nacionais, têm papel importantíssimo na disseminação da literatura científica, por possuírem caráter de publicação regular, além de proporcionarem a reunião dos resultados de pesquisas e sua divulgação mais rápida, estimulando novos trabalhos e promovendo o avanço científico.

Com o passar do tempo, foram surgindo novas áreas científicas, ampliando a pesquisa científica, e ocorrendo um aumento exponencial do número de cientistas e, por conseguinte, da literatura científica. Os novos meios de comunicação viabilizados pela tecnologia da informação aceleraram ainda mais o desenvolvimento da produção científica.

Segundo Meadows (1999), a comunicação científica tem passado por um período de 
evolução rápida causado pelo ambiente eletrônico. As atividades informatizadas parecem destinadas a melhorar a produtividade nos próximos anos permitindo, assim, que continue aumentando a quantidade de informações científicas em circulação. $O$ autor salienta que a antiga diferença entre comunicação formal e informal retorna no meio eletrônico, porém, com menos força. E lembra os aspectos positivos e negativos que acarreta:

Um aspecto negativo importante é que a qualidade da informação proporcionada torna-se de difícil avaliação. Um aspecto positivo importante é que a comunicação eletrônica é mais democrática, no sentido de que tende a atenuar as diferenças entre os participantes, e outro é que estimula a colaboração e o trabalho interdisciplinar (MEADOWS, 1999, p.246).

Harnad (1992) refere que a idéia de criar em 1990 o Scholarly Skywriting tomou por base características do periódico impresso Behavioral and Brain Sciences que, após revisão e seleção dos artigos, oferecia aos autores o serviço de revisão aberta por pares (open peer commentary) envolvendo entre 15 e 25 especialistas de diferentes países e áreas do conhecimento, convidados a escrever comentários sobre a pesquisa. Segundo Sena (2000), essa é a essência dos arquivos abertos de e-prints ${ }^{5}$, especialmente os de preprints, trazendo um novo modelo de comunicação científica para este milênio.

Em 1991, com o início do arXiv, Ginsparg tornou o Laboratório Nacional de Los Alamos o pioneiro na construção de arquivos abertos, considerado hoje um repositório global de trabalhos não-revisados pelos pares nas áreas de Física, Matemática, Ciência da Computação e ciências não-lineares (Sena, 2000). Outro projeto desenvolvido foi o Cognitive Sciences Eprint Archive, da Universidade de Southhampton, no Reino Unido, que aceita trabalhos escritos em qualquer língua, nas áreas de Psicologia, Lingüística, Neurociências e subáreas da Ciência da Computação, Filosofia e Biologia, sendo os trabalhos avaliados preliminarmente por Stevan Harnad (COGPRINTS, 2002).

Para Sena (2000, p.71),

a comunicação científica ampliou seus horizontes de troca de dados, informações e conhecimentos com o aparecimento dos open archives, arquivos que congregam e-prints das diversas áreas do saber e que são abertos à consulta pública [...].

No entanto, a publicação em arquivos abertos, de um modo geral, é de total responsabilidade do autor/pesquisador, em que "a revisão pelos pares e quesito de ineditismo do material não são obstáculos à publicação" (SENA, 2000, p.72).

Eco (2000) manifesta sua preocupação com o que será da sociedade e da cultura na era da Internet:

Pela primeira vez, a humanidade dispõe de uma enorme quantidade de informação a um baixo custo. [...] Uma boa quantidade de informação é benéfica e 0 excesso pode ser péssimo, porque não se consegue encará-lo e escolher o que presta. [...] Como podemos garantir que um jovem iniciante consiga distinguir entre a informação verdadeira e a falsa? (ECO, 2000, p. 11).

Mueller (2000), lembra que o desenvolvimento rápido da Internet e, em particular, dos serviços disponíveis nessa rede desde 1994, modificaram a forma de acesso à informação,

\footnotetext{
${ }^{\mathbf{5}} \mathrm{Harnad}$ explica que "antes de haver arbitragem e publicação, eles são preprints, propriedade do autor. Depois da arbitragem, aceitação e publicação, eles são (em virtude do acordo de copyright), usualmente, propriedade do editor e chamados de reprints" (SEN A, 2000, p.72).
} 
acarretando num período de transição na comunicação científica, em que o sistema de publicação tradicional, bastante rígido, passa para um sistema de publicação eletrônica mais aberta e direta. No entanto, esses dois sistemas começam a mostrar "sinais cada vez mais fortes de convergência, com a crescente introdução de periódicos eletrônicos, que conservam certas características dos periódicos tradicionais". Para a autora, a expressão periódicos eletrônicos designa aqueles periódicos a que se tem acesso mediante o uso de equipamentos eletrônicos, podendo ser divulgados em linha e em CD-ROM. Segundo Mueller, os periódicos distribuídos em CD-ROM diferem muito pouco em relação aos impressos, mantendo o formato em fascículos, a numeração e a periodicidade.

Por fim, Meadows (1999) enfatiza que, apesar do crescimento acelerado e da explosão bibliográfica, o desenvolvimento da ciência e de sua comunicação não ocorreu de forma caótica, atribuindo este fato às regras e práticas, estabelecidas e seguidas pela comunidade científica, para a comunicação entre seus membros.

\section{Artigos e Periódicos Científicos: conceito e estrutura}

A origem do artigo científico vem da correspondência não diplomática trocada entre as várias cortes européias. Este sistema transformou-se num mecanismo de comunicação que rapidamente superou a finalidade inicial. Ao conteúdo intelectual das cartas, foram incluídos gradualmente comentários, revisões e juízos sobre determinados assuntos. Com o tempo, essas cartas passaram a ser um método completo de expressão crítica e a esse sistema deu-se o nome de Republique des Lettres. Naquele período surgiram personagens como o frade Martin Mersenne (1588-1648), que mantinha correspondência com cientistas como Torricelli, Cavalieri, Descartes, Fermat, Gassendi, Pascal e Hobbes, responsáveis por assegurar a circulação das idéias. Um dos resultados mais importantes alcançados pela correspondência científica entre Paris e Londres, por exemplo, foi o fato de introduzir na França os progressos da ciência inglesa e da filosofia experimental de Bacon e, na Inglaterra, a matemática francesa e a filosofia cartesiana. Dessa forma, criou-se um espírito comunitário dentro da comunidade do mundo científico (KRONICK, 1976a).

Com a propagação do novo método de troca de informações, o sistema foi colocado à prova, pois a produção crescente de materiais não era compatível com a capacidade dos homens letrados. Segundo a terminologia atual, a Republique des Lettres sofreu um problema de "largura de banda" e a solução para o dilema veio com a forma impressa, que substituiria o rico mas não sistemático fluxo de correspondências, segundo Guédon citado por Sabbatini (1999).

A criação das sociedades científicas nos anos de 1660 desencadeou o surgimento dos primeiros periódicos científicos. Esses tinham a função de resumir os livros e fatos da cultura em toda a Europa. Isto fez com que os cientistas começassem a escrever artigos ao invés de livros, até aquela época sua única forma de expressão. Foi no início da década de 1850 que os artigos começaram a mencionar as referências a trabalhos anteriores. A transformação do artigo científico em sua forma atual completouse por volta de 1863, embora fosse possível encontrar em 1900 algumas revistas conceituadas com artigos sem qualquer padronização (PRICE, 1976).

Depois de algum tempo, as revistas científicas são compostas basicamente por artigos e tendem a reunir trabalhos de uma mesma área. Os artigos têm por função a divulgação e preservação do conhecimento gerado pela pesquisa, a comunicação entre cientistas e o estabelecimento da prioridade de autoria (MUELLER, 1994; MEDEIROS, 2000). Segundo Ziman (1979, p.108) "a insistência na 
questão da prioridade é necessária para impedir fraudes e plágios; é a assinatura nos títulos de propriedade de nossas realizações". Mueller (1994) salienta que o estabelecimento da prioridade de autoria é uma das únicas funções a ter o consenso da comunidade científica e acadêmica.

Ziman (1979, p.124) lembra que um "artigo publicado numa revista conceituada não representa apenas a opinião do autor; leva também o selo de autenticidade científica através do imprimatur dado pelo autor e os examinadores que ele possa ter consultado".

O conteúdo do artigo científico pode variar, mas normalmente apresenta o resultado de estudos e pesquisas. Pode ser analítico, classificatório, ou argumentativo (MEDEIROS, 2000).

A estrutura do artigo apresenta alterações de acordo com a área de estudo. De um modo geral, possui título; nome do autor, endereço e local de suas atividades; data de recebimento pela revista; data de aceitação do texto revisado para publicação; resumo geralmente em dois ou mais idiomas; introdução; metodologia; resultados; conclusão; referências citadas no texto. Estas também passaram por um período de mudanças e hoje seguem uma forma estruturada de apresentação que pode variar de acordo com a área (MEADOWS, 1999).

A inclusão das palavras-chave nos artigos surge por influência do sistema de indexação baseado em unitermos. Em 1960, o Style Manual for Biological Journals, do American Institute of Biological Sciences, já solicitava aos autores de artigos que selecionassem de cinco a oito palavras que fossem essenciais para a indexação de seu artigo e as colocassem depois do resumo (CONFERENCE..., 1960).

Em relação aos periódicos científicos, a complexidade do seu estudo começa pela própria definição do que sejam essas publicações e de que forma devam ser chamadas.
Meadows (1999) apresenta uma definição mais detalhada do significado das palavras revista, periódico, magazine e publicação seriada, que geralmente confundem e deixam dúvidas na sua utilização. Ele adota, em $A$ comunicação científica, a palavra revista (journal, em inglês) como uma forma abreviada de se referir "a uma coletânea de artigos científicos escritos por diferentes autores. Conjuntos desses artigos são reunidos a intervalos, impressos, encadernados e distribuídos sob um título único".

O desenvolvimento da revista (journal) fez com que houvesse alteração no significado original desta palavra, que seria algo parecido com um jornal (newspaper, em inglês). Contudo, na metade do século XVII ela passa a ser utilizada para denotar uma publicação periódica que contivesse uma série de artigos. Nos séculos seguintes, assume o significado de uma publicação séria que contém idéias originais (MEADOWS, 1999).

$\mathrm{Na}$ literatura brasileira existem alguns termos como: publicações periódicas, periódicos, publicações seriadas e revistas, que podem ser utilizados como sinônimos ou como gênero e espécie. Neste sentido, publicações seriadas são uma categoria maior e mais abrangente, que pode ser definida como "publicações editadas em partes sucessivas, com indicações numéricas ou cronológicas, destinadas a serem continuadas indefinidamente [...] incluem, como espécie, periódicos, jornais, anuários, anais de sociedades científicas [...]" (STUMPF, 2001, p.1).

Os periódicos constituem uma das categorias das publicações seriadas, com as seguintes características:

[...] serem feitas em partes ou fascículos, numeradas progressiva ou cronologicamente, reunidas sob um título comum, editadas em intervalos regulares, com a intenção de continuidade infinita, formadas por contribuições, na forma de artigos 
assinados, sob a direção de um editor, com um plano definido que indica a necessidade de um planejamento prévio (STUMPF, 2001, p.1).

Podem ser divididos em dois grandes grupos: os magazines (revistas, em português), destinados aos leitores não especializados e os journals (revistas científicas ou periódicos científicos, em português), dedicados aos leitores especialistas em determinadas áreas, (STUMPF, 2001).

O uso dos termos 'periódicos científicos' ou 'revistas científicas' é diferenciado pelo profissional que os utiliza. Para a autora os bibliotecários preferem adotar como termo técnico a primeira denominação. Os pesquisadores, professores e estudantes utilizam 'revistas científicas' e muitas vezes apenas 'revistas', pois, considerando o ambiente acadêmico, acham desnecessário qualificá-las como 'científicas' (STUMPF, 2001). Neste trabalho, os termos periódicos científicos e revistas científicas são empregados com o mesmo significado.

\section{Evolução histórica dos periódicos científicos: a busca de critérios de qualidade}

A história dos periódicos científicos teve seu início em 5 de janeiro de 1665, na França, quando o parisiense Denis de Sallo deu início à primeira revista, denominada Journal des Sçavans, dedicada a publicar todo tipo de notícias de interesse científico e cultural. Com o tempo, percebeu-se que era impossível dar atenção a todos os temas que haviam proposto, passando a tratar especificamente dos nãocientíficos (MEADOWS, 1999).

Em março de 1665 surgiram na Inglaterra as Philosophical Transactions, coordenadas pelo Conselho da Royal Society, o qual determinou

\section{[...] que as Philosophical Transactions, a serem preparadas pelo $\mathrm{Sr}$.}

Oldenburg, sejam impressas na primeira segunda-feira de cada mês, caso haja matéria suficiente para isso, e que o texto seja aprovado pelo Conselho, sendo antes revisto por alguns de seus membros [...] (KRONICK, 1976b, p.134).

Como a Royal Society tinha interesse por estudos experimentais, esta revista acabou sendo considerada a precursora do moderno periódico científico (MEADOWS, 1999).

Após a invenção de Gutenberg presenciou-se uma crescente divulgação de idéias e expressões na forma escrita, atingindo escala industrial. Esta situação chamou a atenção para a questão de proteção jurídica do direito autoral. Em 1709, a Inglaterra passou a reconhecer formalmente o copyright, protegendo por 21 anos as cópias impressas de determinadas obras. $\mathrm{Na}$ França, a lei que regulamentou a representação pública das obras nos teatros foi publicada em 1791, e em 1793 é permitida a reprodução das mesmas (GANDELMAN, 2001).

Muitas revistas surgiram na Europa durante o século XVIII. Em 1731, Alexander Monro editou na Inglaterra o primeiro número do periódico Medical Essays and Observations by a Society in Edinburgh (EMERSON, 1979), descrevendo nas suas primeiras páginas 0 conceito de revisão pelos pares (peer review) (KRONICK, 1990), bem como as instruções aos colaboradores e a necessidade do retorno dos artigos aos autores para revisão. Esses procedimentos foram elaborados para tornar os trabalhos mais acessíveis aos leitores (EMERSON, 1979).

No final do século XVIII, começaram a surgir em Paris as primeiras revistas especializadas, destacando-se as Observations sur la Physique, sur l'Histoire Naturelle et sur les Arts, editada desde 1773 por Jean Baptiste François Rozier. Esta revista tornou-se um dos meios mais importantes de comunicação científica do final daquele século, apresentando três itens relacionados à forma do periódico científico: redução 
considerável do tempo necessário para a publicação dos textos enviados aos editores, que durava em torno de seis a oito anos; abertura para publicação de trabalhos de autores de qualquer procedência, e aceitação da língua francesa, de reconhecimento internacional, para a publicação dos artigos (BELMAR; SÁNCHEZ, 2001).

No século XIX, houve um crescente aparecimento de publicações, especialmente na América do Norte e na Europa, destacando-se em 1820 o lançamento do primeiro fascículo do The American Journal of Medical Sciences (MARTINEZ-MALDONADO, 1995). Junto com o aumento das publicações, surgiram dificuldades referentes ao acesso às informações científicas. Ao final desse século, os pesquisadores já necessitavam de ajuda para identificar, em toda a literatura, o material desejado. Parte desse problema era a falta de normalização bibliográfica na elaboração dos relatos de pesquisas, levando à correspondente omissão de dados relevantes. Isto pode ser notado na declaração de um químico em 1890, segundo Bloxham citado por Meadows (1999):

Certo autor me remete a um artigo de Schmidt, nos Berichte da sociedade alemã de química, vol. XX. Como não possuo esta revista, nutro a esperança de conseguir encontrar um resumo do artigo em questão no Journal da Chemical Society, de que sou assinante, porém, como não tenho noção alguma do ano em que foi publicado o vol. XX dos Berichte, tenho de pesquisar em inúmeros índices a fim de encontrar o resumo (MEADOWS, 1999, p.30).

Este comentário indica o método mais importante que estava sendo desenvolvido para superar o problema do acesso. O uso de resumos e índices, considerados como revistas de literatura secundária, foram criadas no século XIX, com a finalidade de facilitar a tarefa de recuperar informações publicadas na literatura primária (MEADOWS, 1999).
De acordo com Ziman (1979), foi a partir de 1850 que as revistas científicas começaram a assumir a funcionalidade que têm atualmente, a de serem veículos para contribuições originais que denotam a noção de rede na estrutura cumulativa da ciência. Isto implica um texto baseado em contribuições anteriores, das quais a nova contribuição se distingue por sua originalidade. Esta intertextualidade marca a noção clássica de método científico.

Recentemente, um elemento relacionado com a identificação de títulos foi introduzido na estrutura do periódico científico. Em 1967, durante a 16 a Conferência Geral da United Nations Educational, Scientific and Cultural Organization (UNESCO) e a Assembléia Geral do International Council for Science (ICSU), foi discutido o projeto de um sistema mundial de informação científica, que se transformou no programa Universal System for Information in Science and Technology da UNESCO. Uma das recomendações desse programa era o estabelecimento de um sistema internacional de registro padronizado das publicações periódicas que facilitasse sua identificação. Após estudos, verificou-se a viabilidade de um sistema de código numérico que as identificaria, independente da área do conhecimento, auxiliando assim o registro e a divulgação das mesmas (CAMPELLO; MAGALHÃES, 1997).

Esta foi a origem do Internacional Standard Serial Number (ISSN), um identificador reconhecido internacionalmente por individualizar o título de uma publicação seriada, tornando-o único e definitivo, facilitando assim o intercâmbio de informações entre diferentes organizações, bases de dados, bibliotecas, editoras, catálogos coletivos nacionais e regionais, entre outros. Identifica ainda o título de uma publicação encerrada, em circulação ou futura, que pode ser escrita em qualquer idioma e distribuída em qualquer suporte físico (INSTITUTO BRASILEIRO..., 2001). 
Em síntese, na evolução do periódico científico podem-se destacar os elementos básicos da estrutura deste tipo de publicação: existência de conselho editorial, periodicidade, revisão por pares, padronização da língua de publicação, normas bibliográficas, existência de sumário, ISSN, indexação em bases de dados e abrangência da revista.

\section{A experiência brasileira}

Após a fundação da Imprensa Régia em 1808, surgiram algumas publicações de especial importância, entre elas Gazeta Médica do Rio de Janeiro e a Gazeta Médica da Bahia, que tiveram seu início, respectivamente, em 1862 e 1866. Surgiu, ainda, a revista Brasil-Médico (1887-1971), que se destacou por publicar trabalhos de pesquisadores brasileiros como Carlos Chagas. Apesar dessas referências pioneiras, foi editada, em abril de 1909, Memórias do Instituto Oswaldo Cruz, uma revista que até 1979 só publicava experiências realizadas no Instituto de Patologia Experimental de Manguinhos, instalado na cidade do Rio de Janeiro e que, por manter um padrão de qualidade e regularidade poucas vezes encontrado em publicações brasileiras, alcançou excelente reputação nacional e internacional. Outro título editado foi a Revista da Sociedade Brasileira de Sciências, atual Anais da Academia Brasileira de Ciências, em 1917 (LEMOS, 1993).

A área da Ciência da Informação tem sua origem em 1937, com a criação do American Documentation Institute, que em 1968 se transformou na American Society for Information Science. No mesmo ano, Harold Borko publicou no American Documentation uma comunicação curta em que procurava definir a Ciência da Informação (BORKO, 1968). Na época, o periódico American Documentation, criado em 1950, teve seu título alterado para Journal of the American Society for Information Science (BRAGA, 1995).
Datam de 1968 as primeiras atividades de pesquisa em Ciência da Informação, especificamente na área de documentação científica, que é um de seus campos de aplicação (GOMES, 1981). Em 1970 foi implantado o Mestrado em Ciência da Informação do Instituto Brasileiro de Bibliografia e Documentação, atual Instituto Brasileiro de Informação em Ciência e Tecnologia, em convênio com a Universidade Federal do Rio de Janeiro. A revista Ciência da Informação foi lançada dois anos depois, em 1972, voltada para o estudo de questões ligadas à informação científica e tecnológica (LEMOS, 1981). Entre outros periódicos, foram publicados: FEBAB: Boletim Informativo, editado em 1960, cujo nome foi alterado em 1973 para Revista Brasileira de Biblioteconomia e Documentação; em 1972 surgiram a Revista de Biblioteconomia de Brasília e a Revista da Escola de Biblioteconomia da Universidade Federal de Minas Gerais - UFMG; esta última, em 1996, teve seu título alterado para Perspectivas em Ciência da Informação (BRAGA, 1995).

A partir do século $X X$, as revistas científicas se disseminaram no meio acadêmico e em instituições de pesquisa. Ressalta-se o interesse dos pesquisadores em promover a comunicação de suas pesquisas para cientistas interessados no assunto, criando normas para esse tipo de publicação, considerada canal primário (formal) de comunicação científica.

Apesar de todos os cuidados no desenvolvimento dessas publicações, Mueller (1999) discute problemas enfrentados pelos editores de periódicos,

Publicados em países que não estão na fronteira do desenvolvimento da ciência e não têm o inglês como língua nacional não têm o prestígio de um periódico de primeira linha. Mesmo que sejam incluídos nos periódicos de resumo da área em que publicam, não conseguem entrar no círculo de periódicos regularmente analisados pelos prestigiosos índices de citação. 
Às vezes seus problemas refletem problemas nacionais de estabilidade política e financeira [...]. Muitos são publicados de forma semi-amadora e têm um esquema de distribuição deficiente. Freqüentemente apresentam irregularidades na periodicidade e morrem com facilidade (MUELLER, 1999, p.1).

Para a autora, muitos desses periódicos que não integram a elite entram em 'agonia' e 'morrem' muito cedo, tanto por falta de bons artigos quanto por falta de recursos financeiros. Outros, apesar de publicarem bons artigos e manterem a periodicidade, não recebem o reconhecimento nem produzem o impacto que mereciam. No Brasil, há aqueles publicados de forma regular durante décadas e outros que foram vítimas da síndrome dos três fascículos. "Entre esses dois extremos se situam muitos outros, freqüentemente irregulares, às vezes acumulando fascículos em uma só edição após períodos de ausência, editados por universidades, departamentos acadêmicos e outras entidades" (MUELLER, 1999, p.3).

Alguns dos problemas relacionados à publicação e à manutenção dos periódicos impressos, como apoio financeiro para produção e questão da distribuição, são solucionados quando da migração para a mídia eletrônica. Nesta, outras questões passam a ter maior relevância, como: visibilidade, recuperação e armazenamento de arquivos.

\section{Periódicos científicos eletrônicos: a manutenção de critérios de qualidade}

A partir dos avanços tecnológicos no século XIX vários inventos influenciaram a forma de comunicação da sociedade, entre eles o rádio, o telefone, o telégrafo e o cartão perfurado de Hermann Hollerith. No início do século XX, surgiram outros meios de comunicação, como a transmissão e a gravação de sons e imagens, a xerografia e os primeiros computadores, assim como novos suportes mecânicos (discos magnéticos e ópticos e fotossensíveis) (DIAS, 1999).

Com o grande volume de documentos circulando na época da Segunda Guerra Mundial, houve a necessidade de buscar novos caminhos para organização, armazenamento e acesso rápido a essas informações. A solução encontrada foi a utilização das microformas, enquanto o arquivamento digital ainda era um desenvolvimento futuro (TENOPIR; KING, 2000). No entanto, Bush (1945) já imaginava e descrevia a máquina Memex, como um dispositivo mecanizado em que uma pessoa guardaria todo e qualquer tipo de documentos (fotos, filmes, revistas, cartas), podendo consultá-los de forma rápida e flexível, como uma extensão de sua memória. Essa máquina seria semelhante a uma mesa com telas translúcidas; teclado; botões; alavancas e mecanismos de armazenamento; gravação e projeção, tomando como base o uso de microfilmes. O Memex permitiria o acesso não-linear a essas unidades individuais de informação multimídia relacionadas por meio de ligações. Para Shneiderman e Kearsley citado por Dias (1999, p.272) "essa idéia de Bush trata do elemento mais importante do hipertexto: os links entre documentos".

As novas invenções trouxeram mudanças ao formato das revistas; na década de 1960, foram utilizadas microformas em substituição à cópia em papel, como opção para diminuir o custo das assinaturas e das remessas postais e o espaço de armazenamento das revistas. Esta alternativa não foi bem recebida pelos assinantes e usuários das bibliotecas, sendo hoje utilizada apenas como uma forma de obtenção de volumes antigos (STUMPF, 1996).

No mesmo período, surgem projetos que passam a utilizar computadores eletrônicos. Segundo Meadows (1999) esses equipamentos, criados na década de 1940, foram empregados no processamento de informações bibliográficas 
nos anos de 1960, por oferecerem duas vantagens: armazenamento de um grande volume de informações e ordenação rápida das mesmas. No entanto, a questão consistia em como utilizar essas vantagens com a finalidade de localizar itens da literatura que fossem pertinentes à necessidade dos usuários. Esta questão levou ao desenvolvimento do método clássico que utiliza a busca por palavras-chave.

Em 1958, Luhn já demonstrava o uso do computador na "elaboração automática de extratos", comumente denominada "redação automática de resumos".

Na década de 1960, o Chemical Titles foi a primeira publicação de sumários a utilizar o índice Keyword-in-context (KWIC) considerado um método simples de produção de índices impressos por computador, não demorando a surgirem outras bases de dados com consulta remota (CHARTRON, 2002).

Segundo Garfield (1979), o computador era utilizado praticamente na geração de índices que eram fotografados para confecção de fotolitos que seriam utilizados como matriz de impressão offset. Em agosto de 1964 é dado o grande passo no sistema de publicações, quando o Index Medicus, produto da Medlars, reúne numa única operação a organização do conteúdo (as referências em ordem alfabética) e o índice de autores e a fotocomposição com a produção automática dos fotolitos. Na mesma época, surge o Graphic Arts Composing Equipment, que utiliza 226 caracteres diferentes, possibilitando a quebra da monotonia visual dos textos até então produzidos por impressoras matriciais equipadas apenas com caixa alta e sem acentos diacríticos.

Nesse período é possível identificar um número crescente de bases de dados, tanto bibliográficos quanto não-bibliográficos, legíveis por computador. Muitas dessas coleções de dados ou informações podiam ser acessadas nos formatos impresso e eletrônico, sendo que a coexistência das duas formas foi designada por Lancaster (1993) como publicação dúplex.
Desde a década de 1960, os computadores eletrônicos, embora caros, tornaram-se um canal cada vez mais aceito para publicações secundárias (resumos e índices), que tiveram um crescimento exponencial a partir das décadas de 1970 e principalmente 1980, com a implantação dos microcomputadores, que se tornaram mais acessíveis e de uso mais fácil (MEADOWS, 1999).

A partir da década de 1970, o uso do computador trouxe avanços na editoração eletrônica, melhorando a qualidade e aumentando a rapidez na edição das revistas. $A$ primeira realização foi o Electronic Information Exchange System, desenvolvido nos Estados Unidos entre 1978 e 1980. O sistema incluía artigos, uma caixa postal, um boletim dirigido por um editor e um caderno de anotações (CHARTRON, 2002). Entre as tentativas de informatizar todo o processo editorial, destacamse os Centros de Processamento Editorial (EPC), desenvolvidos nos Estados Unidos no início dos anos de 1970, e Birmingham and Loughborough Eletronic Network Development (BLEND), desenvolvido na Inglaterra na década de 1980 (STUMPF, 1996).

Os EPC patrocinados pela National Science Foundation constituíram-se em empreendimento cooperativo entre publicadores, com a finalidade de oferecer suporte automatizado para todas as etapas envolvidas na produção das revistas, visando à redução dos custos. Estas vão da submissão do trabalho pelo autor e a avaliação pelos pares, até a editoração, impressão e administração das revistas. As dificuldades para a viabilização desses centros foram referentes à incompatibilidade dos equipamentos e processadores de texto dos autores e dos revisores. Pode-se dizer que alguns desses problemas foram solucionados e um bom número das revistas americanas encontra-se totalmente automatizado (STUMPF, 1996; TENOPIR; KING, 2000). 
No período de 1980 a 1984, as Universidades de Birmingham e Loughborough desenvolveram o projeto BLEND, visando a avançar um pouco mais na produção de revistas. Além de automatizar todas as etapas do processo, o projeto, financiado pela Brithish Library, constituiu-se em uma alternativa de substituição total da publicação impressa por armazenamento digital e acesso eletrônico aos artigos. Entre as dificuldades para viabilização do programa incluem-se a incompatibilidade dos equipamentos e programas e o alto custo para implantação (MCKNIGHT, 1995; STUMPF, 1996; CHARTRON, 2002). Apesar dos problemas, o programa resultou na revista Computer Human Factors, que era acessada via terminal remoto, conectado a um computador central por intermédio de uma rede local (MCKNIGHT, 1995; ALMEIDA et al., 1996).

Lancaster (1985) ressalta que periódicos eletrônicos vêm servindo apenas para a distribuição do material gráfico, sem acrescentar qualquer tipo de característica específica de publicação eletrônica. O autor apresenta uma escala de seis estágios no processo "evolutivo" dessas revistas, até atingir a era totalmente digital. O primeiro estágio caracteriza-se apenas pela produção de uma publicação impressa; o segundo acrescenta a distribuição do periódico impresso no formato eletrônico; o terceiro surge com novas publicações criadas e distribuídas apenas no meio digital, mas mantendo características herdadas da revista tradicional. A partir do quarto estágio deve ocorrer um maior desenvolvimento desse tipo de publicação, incorporando recursos pertinentes ao meio eletrônico, tais como links entre autores e leitores, interação do usuário com o conteúdo, utilização de recursos multimídia, até alcançar no sexto e último estágio uma integração dos recursos de interação/colaboração com os recursos multimídia.

Em 1991 houve a implantação e especificação de um conjunto de itens, possibilitando a troca de hipertexto em rede, como: programa editor de hipertexto WorldDwidEweb, junto ao servidor de Rede da comunidade Hight Energy Physics; navegador em "modo de linha"; Identificador Universal de Documentos (hoje URLs); HyperText Markup Language (HTML); HypertText Transfer Protocol (http), e Browser Mosaic. Esses elementos contribuíram para a criação da World Wide Web (WWW ou Web), em setembro de 1994, revolucionando o uso da Internet, aumentando a transferência de informações neste meio, por ser um método eficiente na distribuição de hipertextos e no acesso a sons e imagens (BERNERS-LEE, 2002).

No mesmo período surgiu o sucessor do projeto BLEND, denominado Quartet, com principal propósito de investigar as implicações da tecnologia da informação no processo de comunicação acadêmica. Este programa foi o responsável pelo surgimento da primeira revista eletrônica hipertextual HyperBIT (Behaviour and Information Technology), que permitia ao usuário movimentar-se de forma rápida e fácil entre os artigos utilizando os links definidos pelo autor (ALMEIDA et al., 1996; MCKNIGHT, 1995).

Em 1991, foi iniciado o The University Licensing Program (TULIP), concluído em 1995, consistindo num projeto colaborativo entre a editora científica Elsevier Science e nove universidades dos Estados Unidos, visando à implementação de componentes de bibliotecas digitais no meio acadêmico. Do relatório final do projeto (TULIP, 1996) constam resultados do trabalho de avaliação da distribuição, via rede, de 43 publicações científicas em formato eletrônico às universidades participantes. Estas desenvolveram ou adaptaram sistemas para distribuição desses periódicos para os computadores dos usuários finais. A pesquisa focalizou questões técnicas, comportamento do usuário, e questões organizacionais e econômicas.

Entre os requisitos indicados pelos usuários, destacam-se: facilidade de uso, acesso 
a toda informação por meio de uma única fonte, sistema eficaz de busca, processamento rápido para download e impressão, recuperação rápida da informação, boa qualidade de imagem e texto, cobertura satisfatória tanto no que se refere aos periódicos quanto ao período de tempo abrangido, existência de vínculos entre distintos componentes de informação.

O projeto foi bem aceito pela comunidade acadêmica, sendo mais usado pelos alunos; a maioria dos usuários considerou que a cobertura dos títulos era insuficiente. Além disso, equipamentos e programas constituíram um sério obstáculo para o uso adequado da informação veiculada pelo TULIP. A cooperação entre as parcerias, o levantamento das necessidades e dos interesses do usuário e a existência de uma infraestrutura adequada são pontos cruciais para a implementação de projetos dessa natureza (TULIP, 1996).

Sintetizando o que representou o TULIP para as instituições envolvidas, o projeto contribuiu para a reflexão sobre as questões críticas levantadas durante a pesquisa, visando a aperfeiçoar o trabalho de bibliotecas no que se refere a: levantamento, seleção e disponibilidade da informação de que a comunidade necessita, orientando o usuário para a informação adequada, bem como proteção de direitos autorais.

Finalmente, em 1991 a American Association for the Advancement of Science e a Online Computer Library Center lançaram o The Online Journal of Current Clinical Trials, um periódico distribuído na Internet utilizando a Standard Generalized Markup Language (SGML), padrão de descrição de textos que possibilitou a publicação de imagens e tabelas e que deu origem ao HTML (LANGSCHIED, 1994). Na mesma época, outros projetos foram desenvolvidos, entre eles o Chemistry Online Retrieval Experiment (CORE) da Cornell University, Rede Sage Project da University of Califórnia e o Journal Storage (JSTOR) da Fundação Andrew W. Mellon. O estabelecimento do JSTOR como pesquisa visava a investigar a viabilidade econômica da solução digital, em relação ao problema do armazenamento físico da literatura científica. Utilizando a digitalização dos arquivos antigos, combinados com um arquivo de texto simples, permitia a realização de buscas dentro do conteúdo (JOURNAL..., 2002).

Após a implantação da Web, surgem publicações eletrônicas como o Super Journal Project, iniciado em 1995 dentro do âmbito do Eletronic Libraries Programme. O projeto contou com a colaboração de editores, universidades e bibliotecas visando ao desenvolvimento de revistas eletrônicas hipertextuais. Foi desenvolvida uma variedade de versões eletrônicas de revistas que mantinham critério de avaliação por pares e possuíam reputação na comunidade científica. As principais áreas escolhidas foram: Genética Molecular; Polímeros e Físico-química; Comunicação e Estudos Culturais; Ciência Política e Ciências da Computação. Além disso, os títulos selecionados apresentavam potencial para a inclusão de multimídia em seu conteúdo, como a visualização de estruturas químicas complexas tridimensionais, no caso das revistas de Química; rotinas e programas descritos em artigos de revistas de Computação, assim como simulações em linha e resultados na forma de bases de dados utilizáveis. Todos os periódicos publicavam dados de experimentos ou estudos estatísticos. O projeto foi encerrado em dezembro de 1998, com o fim do financiamento concedido pela Joint Information Systems Committee do Higher Education Funding Councils (OPEN JOURNAL..., 2002).

\section{Projetos brasileiros}

Segundo Packer et al. (1998a), a comunicação científica nacional encontra-se em momento propício para combater e superar as dificuldades de divulgação dos resultados de pesquisas existentes. A publicação de periódicos científicos na Internet proporciona, por si só e 
de imediato, um grande aumento na acessibilidade e na sua exposição universal. Contudo, para assegurar amplo acesso e visibilidade, a publicação eletrônica deve ser complementada e certificada por índices ou bases de dados que as referenciem e qualifiquem. Os autores salientam que a publicação nacional, em seu conjunto, requer mecanismos e instrumentos de avaliação do seu uso, da sua qualidade e do seu impacto. Apontam, ainda, a necessidade de promover a publicação eletrônica brasileira mediante mecanismos integrados de controle de qualidade e de avaliação.

Em 1994 foi iniciado o projeto do The Journal of Venomous Animals and Toxins (JVAT), editado pelo CEVAP da Universidade Estadual Paulista (UNESP), Botucatu, São Paulo. Tendo a língua inglesa como padrão para publicação, teve seu primeiro fascículo distribuído em março de 1995.

O desenvolvimento da revista hipertextual tomou por base os critérios utilizados na criação de um periódico impresso, mantendo-se inclusive a paginação contínua e a legenda em todas as páginas. A revista foi desenvolvida inicialmente no editor de textos Word 2.0 para Windows $^{(R)}$ e compilada com Help Compiler (HCP), gerando um arquivo em formato Help para ser executado na plataforma Windows ${ }^{(\mathrm{R})}$. O usuário podia optar pela impressão total ou parcial em papel, ou por fazer a leitura do(s) artigo(s) na tela do computador.

A partir do terceiro fascículo, foram utilizados programas auxiliares no desenvolvimento de arquivos Help. A plataforma utilizada possibilitou uma rápida evolução na forma de distribuição da revista, no início em discos magnéticos, atualmente em CD-ROM e em linha na Scientific Electronic Library Online (SciELO). Salienta-se a dificuldade na recuperação dos artigos publicados desde 1995. Este problema deve-se à rápida atualização dos programas utilizados para o desenvolvimento da revista, o que levou o CEVAP a estudar a possibilidade de dispor a revista na Internet em site próprio.

Em 1994 teve início o projeto de publicação científica eletrônica na Internet como divisão interna do Núcleo de Informática Biomédica da Universidade Estadual de Campinas. O Grupo de Publicações Eletrônicas em Medicina e Biologia (e*pub) foi responsável pelo desenvolvimento de revistas como: Arquivos Brasileiros de Cardiologia, Online Journal of Plastic and Reconstructive Surgery e Revista da Sociedade de Cardiologia do Estado de São Paulo. Desenvolveu e fomentou a publicação eletrônica no âmbito da comunicação primária e revistas voltadas ao público leigo como a Saúde e Vida Online, que constituiria uma nova forma de comunicação de informações em Saúde, permitindo a interação entre médicos e pacientes (E*PUB, 2002). O site da $e^{*}$ pub $^{6}$ mantém os títulos disponíveis no meio eletrônico, mas percebe-se a descontinuidade das publicações a partir de 1997.

Destaque deve ser dado à SciELO, biblioteca eletrônica que abrange uma coleção selecionada de periódicos científicos brasileiros, de diferentes áreas do conhecimento. É o resultado de um projeto de pesquisa da Fundação de Amparo à Pesquisa do Estado de São Paulo em parceria com o Centro Latino-Americano e do Caribe de Informação em Ciências da Saúde (BIREME). A biblioteca utiliza a Metodologia SciELO para preparação, armazenamento, disseminação e avaliação de publicações científicas em formato eletrônico.

Atualmente a biblioteca está expandindo a metodologia SciELO para outros países da América Latina. Destacam-se os recursos disponíveis ao usuário que, além de acessar os artigos científicos na íntegra, pode obter a estatística de acessos e de impacto de cada periódico participante do projeto (MENEGHINI, 1998; PACKER et al., 1998b), que vem se

${ }^{6}$ Disponível em http://www.epub.org.br, acesso em 29 jun. 2002. 
consolidando e aumentando as atividades, permitindo a inclusão de novos títulos de periódicos à coleção.

A SciELO oferece links dinâmicos para o Curriculum Vitae dos pesquisadores cadastrados na Plataforma Lattes $^{7}$, que têm seus artigos publicados em periódicos da coleção, permitindo ao leitor o acesso à produção científica dos mesmos disponível na biblioteca eletrônica e informação de como referenciar os artigos. A partir de 2002, passou a contar com o apoio do Conselho Nacional de Desenvolvimento Científico e Tecnológico.

No Brasil, as mudanças trazidas pelas novas tecnologias vêm incentivando a publicação de periódicos exclusivamente eletrônicos. Muitos ainda mantêm características do impresso e começam a implementar opções multimídia. Alguns exemplos foram localizados na Internet, sendo um pequeno número desenvolvido no âmbito de programas de pós-graduação. Com as facilidades da edição eletrônica e a agilidade da mídia na divulgação de pesquisas, a tendência parece ser o surgimento de novos títulos eletrônicos subordinados a instituições acadêmicas.

Nessa transição do periódico impresso em papel para o periódico eletrônico, destacam-se as novas exigências apontadas nos diferentes projetos de desenvolvimento deste tipo de periódico, relacionadas diretamente à rápida evolução da tecnologia. Com seus avanços, ao mesmo tempo que permitiu o aperfeiçoamento dos suportes físicos de armazenamento, dos processos de descrição e indexação utilizados nos sistemas de gerenciamento de informação, bem como das formas de recuperação e disseminação da informação científica, a tecnologia possibilitou a produção de novas formas de edição de periódicos científicos.

$\mathrm{Na}$ atualidade, observa-se a coexistência da mídia impressa e da eletrônica, ao lado de um número crescente de publicações eletrônicas. Baseando-se em Lancaster (1985), pode-se afirmar que os periódicos eletrônicos encontram-se numa fase de transição do terceiro para o quarto estágio de evolução tecnológica, isto é, começam a ser desenvolvidos e distribuídos periódicos somente em mídia eletrônica e com incorporações de recursos de multimídia. No entanto, em geral, apresentam características estruturais do periódico tradicional. Por outro lado, é preciso destacar, nessa evolução, a necessidade da permanência dos indicadores de qualidade exigidos para o periódico impresso, na revista eletrônica.

Finalmente, é preciso considerar que a passagem da sociedade acústica para a sociedade tipográfica e desta para a sociedade eletrônica provocou modificações na estrutura da comunicação do conhecimento, trazendo diferentes formas de armazenamento, transmissão e acesso linear e não-linear à informação, com repercussões no desenvolvimento de periódicos científicos eletrônicos. Essas mudanças serão sintetizadas a seguir.

\section{Processos de leitura com acesso linear e não-Linear e periódico eletrônico}

Na evolução da comunicação científica a invenção da imprensa possibilitou aos leitores o acesso aos textos, fazendo com que a leitura e a interpretação tivessem um caráter mais individualizado e, com isso, os impressos evoluíram e passaram a incluir gráficos, tabelas, mapas e quadros mais precisos em suas representações. A união dessas características a outras já existentes, como a paginação, o índice, o sumário, permitiu ao leitor avaliar o conteúdo da obra de forma mais rápida, bem como buscar as partes que mais the interessavam, de uma forma seletiva e não linear. A utilização, nos textos, de notas de rodapé ou

\footnotetext{
${ }^{7}$ Formulário eletrônico para o cadastro de dados curriculares de pesquisadores e de usuários de Ciência eTecnologia em geral, no Brasil (SciELO NEWS, 2002)
} 
referências cruzadas levou o usuário a ter conhecimento de outras literaturas ligadas à área de estudo demonstrando, também, uma certa tendência à não linearidade (NIELSEN, 1995; DIAS, 1999).

Nesse momento da História surge o acesso fragmentado ou não-linear à informação, hoje incrementado pelo uso da Informática. O avanço tecnológico permitiu a criação do hipertexto, um arquivo não seqüencial, em que não há uma ordem única a determinar a seqüência de leitura do texto, ficando a cargo do leitor a escolha do fluxo da informação (NIELSEN, 1995). O texto passa a ter pontos de acesso diretos, o que pode tornar a recuperação da informação mais rápida e eficiente, sendo esta uma das vantagens presentes no periódico científico eletrônico.

Cabe salientar que a linearidade permanece no texto, mas a leitura ganha caráter mais individualizado, deixando o leitor trabalhar o texto de forma seletiva e não-linear.

Tecnicamente, um hipertexto é um conjunto de nós ligados por conexões. Os nós podem ser palavras, páginas, imagens, gráficos ou partes de gráficos, seqüências sonoras, documentos complexos que podem eles mesmos ser hipertextos. Os itens de informação não são ligados linearmente, como em uma corda de nós, mas cada um deles, ou a maioria, estende suas conexões em estrela, de modo reticular $[\ldots]$. Finalmente, um hipertexto é um tipo de programa para a organização de conhecimentos ou dados, a aquisição de informações e a comunicação (LÉVY, 1993, p.33).

Algumas considerações merecem a atenção no que diz respeito à construção dos sistemas hipertexto e às orientações para a sua utilização.

O acesso não-linear às informações pode acarretar a desorientação do leitor, que encontra dificuldades em se localizar dentro da rede informacional escolhida. A desorientação tam- bém é provocada quando este percorre os links de um texto e, ao acessar um determinado tipo de página, tem a sua trilha de navegação rompida. Ao tentar refazê-la, utilizando o folheio, percebe que não há mais a seqüência de links das informações acessadas anteriormente.

Nielsen (1995) chama a atenção de autores de hipertextos que ligam seus documentos a textos localizados em um site remoto. Estes, ao mudarem a estrutura de arquivo, acabam "quebrando" esses links, levando a uma conseqüente interrupção do acesso à informação.

Moscoso citado por Vilan Filho (1994), apresentou alguns problemas importantes associados aos sistemas hipertextuais, tais como:

- a movimentação de tela em tela pode conduzir à aquisição de um conhecimento superficial;

- vídeo e som pressupõem recuperação passiva do conhecimento;

- os sistemas hipermídia são concebidos para serem experimentados interativamente e não para serem impressos. Quando se imprime determinadas partes, perde-se a argumentação implícita criada pelas ligações de nós;

- os sistemas são concebidos para que o usuário folheie e se desloque pelo sistema;

- o entendimento incompleto das associações leva a uma má interpretação do sentido da estruturação (VILAN FILHO, 1994, p.302).

Uma vez que sistemas hipertextuais estão relacionados diretamente com a mídia eletrônica, em particular com a Internet, as características do hipertexto aqui sintetizadas devem ser levadas em consideração durante o desenvolvimento de periódicos científicos eletrônicos, visando a aperfeiçoar a estruturação do sistema de acesso e transferência de informações científicas, necessárias à construção do conhecimento. 


\section{REFERÊ N CIAS}

ALMEIDA, R.L.; PARANHOS, B.S.; FLORENTINO, C.A.A. Buscando soluções para se publicar na Internet: a experiência do IBICT com a Ciência da Informação on-line. Ciência da Informação, Brasília, v.25, n.3, p.454-460, 1996.

BELMAR, A.G.; SÁNCHEZ, J.R.B. Las fuentes de información en historia de la ciencia. Instrumentos de recuperación y técnicas de análisis. p.1-19, 2001. Disponible em: <http://www.ua.es/dsp/antonio/ matdoc/myt/fuentes/fuentes.html>. Acesso em: 7 Oct. 2001.

BERNERS-LEE, T. The World Wide Web: a very short personal history. Available from: <http:// www.w3.org/People/Berners-Lee/ShortHistory. html>. Acess: 1 Apr. 2002.

BORKO, H. Information science: what is it ? American Documentation, Washington, v.19, n.1, p.3-5, 1968.

BRAGA, G.M. Informação, ciência da informação: breves reflexões em três tempos. Ciência da Informação, v.24, n.1, p.84-88, 1995.

BUSH, V. As we may think. The Atlantic Mountly, n.1, p.101-108, July, 1945. Available from: <http:// www.theatlantic.com/unbound/flashbks/computer/ bushf.htm>. Acess: 12 Feb. 2001.

CAMPELLO, B.S.; MAGALHÃES, M.J.A. Introdução ao controle bibliográfico. Brasília: Briquet de Lemos, 1997. p.70-74.

CHARTRON, G. La presse périodique scientifique sur les réseaux. Disponible de: <http://www.info. unicaen.fr/bnum/jelc/solaris/d03/3chartron.html>. Acess: 4 Apr. 2002.

COGPRINTS. Cognitive Sciences Eprint Archive. Available from: <http://cogprints.soton.ac.uk>. Acess: 26 Abr. 2002.

CONFERENCE OF BIOLOGICAL EDITORS. Committee on form and style. Style manual for biological journals. Washington: American Institute of Biological Sciences, 1960. p.36.

DIAS, C.A. Hipertexto: evolução histórica e efeitos sociais. Ciência da Informação, Brasília, v.28, n.3, p.269-277, 1999.

ECO, U. O dilúvio da informação. Veja vida digital, São Paulo, edição 1681/A, v.33, n.4, p.11-15, 2000.
EMERSON, R.L. The Philosophical Society of Edinburg 1731-1747. British Journal for the History of Science, Buckinghamshire, v.12, p.154-191, 1979. E*PUB. Centros de pesquisa e publicação. Disponível em: <http://www.webpraxis.com/msabba/ epub-5.htm>. Acesso em: 5 abr. 2002.

GANDELMAN, H. De Gutenberg à Internet: direitos autorais na era digital. Rio de Janeiro: Record, 2001. p.27-57.

GARFIELD, E. Some reflections on Index Medicus. Essays of an Information Scientist, Amsterdan, v.4, p.341-347, 1979.

GOMES, H. E. Como vai o sistema de comunicação na Ciência da Informação? Ciência da Informação, Brasília, v.10, n.1, p.71-73, 1981.

HARNAD, S. Interactive publication: extending the American Physical Society's discipline-specific model for electronic publishing. Serial Review, p.58-61, 1992. Available from: <http://www.cogsci. soton.ac.uk/ harnad/Papers/Harnad/harnad92. interactivpub.html>. Acess: 2 Feb. 2000.

INSTITUTO BRASILEIRO DE INFORMAÇÃO EM CIÊNCIA E TECNOLOGIA. ISSN: número internacional normatizado para publicações seriadas. Disponível em: <http://www.ibict.br/issn>. Acesso em: 29 abr. 2001.

JOURNAL STORAGE. The need for JSTOR. Avaliable from: <http://www.jstor.org/about/ need.html>. Acess: 4 Apr. 2002.

KRONICK, D.A. Antecedent and contemporary forms of communication. In: KRONICK, D.A. A history of scientific and technical periodicals. 2. ed. Metuchen: Scarecrow Press, 1976a. p.53-76.

KRONICK, D.A. Original publication: society proceedings. In: KRONICK, D.A. A history of scientific and technical periodicals. 2.ed. Metuchen: Scarecrow Press, 1976b. p.134.

KRONICK, D.A. Derivative publication: the abstract journal. In: KRONICK, D.A. A history of scientific and technical periodicals. 2.ed. Metuchen: Scarecrow Press, 1976c. p.171-183.

KRONICK, D.A. Peer review in $18^{\text {th }}$ century scientific journalism. The Journal of the American Medical 
Association, Chicago, v.263, n.10, p.1321-1322, 1990.

LANCASTER, F.W. The paperless society revisited. American Libraries, v.16, n.8, p.553-555, 1985.

LANCASTER, F.W. Indexação e resumos: teoria e prática. Brasília: Briquet de Lemos, 1993. p.229-272.

LANGSCHIED, L. Eletronic Journal Forum: VPIEJ-L: An online discussion group for eletronic journal publishing concernes. Serial Review, v.20, n.1, p.80-89, 1994.

LEMOS, A.A.B. A nova fase de Ciência da Informação. Ciência da Informação, Brasília, v.10, n.1, p.69-70, 1981.

LEMOS, A.A.B. Análise crítica de uma revista institucional: as Memórias do Instituto Oswaldo Cruz. Cadernos de Saúde Pública, Rio de Janeiro, v.9, n.2, p.161-169, 1993.

LÉVY, P. As tecnologias da inteligência: o futuro do pensamento na era da informática. Rio de Janeiro: Editora 34, 1993. 203p.

LUHN, H.P. The automatic creation of literature abstracts. IBM Journal of Research and Development, v.2, p.159-165, 1958.

MARTINEZ-MALDONADO, M. The world and medicine in and around the time of the first issue (1820) of The American Journal of the Medical Sciences. American Journal of the Medical Science, Philadelphia, v.310, n.1, p.1-2, 1995.

MCKNIGHT, C. Electronic journals - past, present... and future? Aslib Proceedings, London, v.45, n.1, p.7-10, 1993.

MCKNIGHT, C. Digital Library research at Loughborough: the last fifteen years. 1995. Available from: <http://www.csdl.tamu.edu/DL95/papers/ mcknight/mcknight.html>. Acess: 4 Abr. 2002.

MEADOWS, A.J. A comunicação científica. Brasília: Briquet de Lemos, 1999. 268p.

MEDEIROS, J.B. Redação científica: a prática de fichamentos, resumos, resenhas. 4.ed. São Paulo: Atlas, 2000. 237p.

MENEGHINI, R. Avaliação da produção científica e o Projeto SciELO. Ciência da Informação, v.27, n.2, p.219-220, 1998.
MUELLER, S.P.M. O círculo vicioso que prende os periódicos nacionais. DataGramaZero - Revista de Ciência da Informação, n. zero, p.1-8, 1999. Disponível em: <http://www.dgzero.org/dez99/ Art_04.htm>. Acesso em: 16 jun. 2000.

MUELLER, S.P.M. O impacto das tecnologias de informação na geração do artigo científico: tópicos para estudo. Ciência da Informação, Brasília, v.23, n.3, p.309-317, 1994.

MUELLER, S.P.M. O periódico científico. In: CAMPELLO, B.S., CENDÓN, B.V., KREMER, J.M. (Ed.). Fontes de informação para pesquisadores e profissionais. Belo Horizonte: UFMG, 2000. p.73-95.

NIELSEN, J. Multimídia e hipertexto: a Internet e além dela. New York: Academic Press, 1995. 480p. Disponível em: <http://nt-labes.icmc.sc.usp.br/ cursos/sce225/pNielsen.htm>. Acesso em: 16 fev. 2001.

OPEN JOURNAL PROJECT: Final report to eLib. Available from: <http://www.soton.ac.uk>. Acess: 24 Mar. 2002.

PACKER, A.L.; ANTONIO, I.; BERAQUET, V. S. M. Rumo à publicação eletrônica. Ciência da Informação, Brasília, v.27, n.2, p.107-108, 1998a.

PACKER, A.L. et al. SciELO: uma metodologia para publicação eletrônica. Ciência da Informação, Brasília, v.27, n.2, p.109-121, 1998b.

PRICE, D.J.S. O desenvolvimento da ciência. Rio de Janeiro: Livros Técnicos e Científicos, 1976. 96p.

SABBATINI, M. Evolución histórica de lãs publicaciones científicas: de la Republique des Lettres hasta la World Wide Web. Salamanca, 1999. Trabalho de curso apresentado ao Máster Ciência, Tecnologia y Sociedad. Universidad de Salamanca, 1999. Disponível em: <http://www. webpraxis.com/msabba/artigos/acad003evolucion.htm>. Acesso em: 24 set. 2000.

SENA, N.K. Open archives: caminho alternativo para a comunicação científica. Ciência da Informação, Brasília, v.29, n.3, p.71-78, 2000.

STUMPF, I.R.C. Passado e futuro das revistas científicas. Ciência da Informação, Brasília,v.25, n.3, p.383-386, 1996. 
STUMPF, I.R.C. Reflexões sobre as revistas brasileiras. Disponível em: <http://www.ilea.ufrgs. br/intexto/v1n3/a-v1n3a3.html>. Acesso em: 8 ago. 2001.

TENOPIR, C.; KING, D.W. Towards electronic journals: realities for scientists, librarians, and publishers. Washington: Special Libraries Association, 2000. 488p.
TULIP. Final report. July 18, 1996. Available from: <http://www.elsevier.nl/homepage/about/resproj/ trmenu.htm>. Acess: 1 Abr. 2002.

VILAN FILHO, J.L. Hipertexto: visão geral de uma nova tecnologia de informação. Ciência da Informação, Brasília, v. 23, n. 3, p.295-308, 1994.

ZIMAN, J. Conhecimento público. São Paulo: Itatiaia, 1979. 163p. 
